Lep. Rev. ( I $\left.^{6} 65\right), \mathbf{3}^{6}, \mathrm{I}, 35 / 36$

\title{
A Varicelliform Eruption appearing in the course of Acute Exacerbation of Lepromatous Leprosy
}

\author{
S. G. BROW NE, M.D., F.R.C.P., F.R.C.s., D.T.M. \\ Leprosy Service Research Unit, Uzuakoli, Eastern Nigeria
}

The well-known skin lesions that occur during acute exacerbation in lepromatous leprosy assume many and diverse forms. One of the least common is a varicelliform eruption.

CASE REPORT

The patient was an Ibibio male of about 35 years of age. He was admitted to the Uzuakoli Leprosy Settlement on 22nd February, 1964, suffering from lepromatous leprosy of probably three years' duration.

\section{Clinical examination}

The skin of the entire body except for the scalp, the axillae, the inguinal regions and the sacrococcygeal region was diffusely infiltrated and almost uniformly hypopigmented. He had not noticed the gradual loss of pigment or the thickening of the integument, but the sudden appearance of numerous lenticular nodules on his face (especially the forehead, cheeks, nose and chin), upper trunk and proximal parts of the limbs brought him for diagnosis and treatment.

Both the ulnar nerves were slightly enlarged just above the elbow, and tender. The other main superficial nerve trunks were normal.

\section{Bacteriological examination}

His Bacterial Index was high (4.0), innumerable bacilli and many globi being present in every field examined with the oil-immersion objective from every site smeared.

\section{Mitsuda reaction}

The Mitsuda reaction was completely negative.

\section{Treatment}

After the first dose of $0.025 \mathrm{~g}$. dapsone, several lesions of erythema nodosum leprosum - both acuminate and diffuse - made their appearance on the forearms, arms and thighs. The temperature rose to $100.8^{\circ} \mathrm{F}$. $\left(38.2^{\circ} \mathrm{C}\right.$.) The general symptoms were controlled by rest in bed and analgesics, and since no further local lesions occurred in the skin, dapsone was continued at the same dose, $0.025 \mathrm{~g}$. twice weekly. With two months, the Bacterial Index (eight sites smeared) had fallen from 4.0 to 2.5 and the percentage of normal-staining bacilli from 87 to 13 .

\section{The varicelliform eruption}

The dose of dapsone was then increased to $0.05 \mathrm{~g}$. twice weekly. Within two days of receiving the first dose of $0.05 \mathrm{~g}$., the patient complained of general malaise, accompanied by a slightly raised temperature. In many areas, the lepromatous infiltration of the skin of the face, trunk and limb became red and raised and papular. On the acuminate papules of many of the infiltrated masses, particularly on the chest and the scapular region, small vesicles numbering about a score suddenly made their appearance. These latter itched slightly. The individual elements were observed to maturate rapidly from the papular to the vesicular stage. Some of the vesicles burst spontaneously; others were scratched by the patient. Successive crops appeared during the following two weeks. No vesicles appeared on the lepromatous nodules themselves.

Microscopical examination of the opalescent fluid obtained from intact vesicles revealed scanty degenerate pus cells and very numerous $M$. leprae, arranged singly and normal-staining. No other organisms were found, in smears stained by either methylene blue or Gram's method.

Since there had been no cases of chickenpox 
or of herpes zoster in the Settlement, these two conditions may be excluded.

All the varicelliform lesions eventually crusted over and scarred. The acute exacerbation subsided, and the patient resumed his interrupted clinical progress and his bacteriological improvement.

SUMMARY

A case is reported in which a varicelliform eruption appeared on infiltrated skin lesions during acute exacerbation in lepromatous leprosy. The vesicles contained numerous $M$. leprae.

A CKNOWLEDGEMENTS

My thanks are due to Dr S. O. Egwuatu, Chief Medical Officer, Ministry of Health, Eastern Nigeria, for permission to publish this article. 